\title{
An empirical and forecasting analysis of the bioenergy market in the EU28 region: evidence from a panel data simultaneous equation model
}

\begin{abstract}
This study improves upon and applies a comprehensive panel data simultaneous equation model to the European Union (EU28) region's bioenergy market. The goals are to estimate bioenergy quantities in domestic and international markets for the period from 1990 to 2013 and to apply a forecasting analysis for the EU28's domestic and international bioenergy markets for the period of 2014-2020. The results demonstrate that biomass harvest and the domestic price in a domestic market have a significant influence on the supply function. Additionally, domestic price has a negative relationship with the bioenergy market domestic demand. In international markets, competitive import prices play a primary role in the development of the bioenergy market import demand. Export prices and GDP also have primary influences on the export demand for bioenergy. Moreover, the exchange rate has a positive and significant effect on export demand. The results of a forecasting analysis for the future period of 2014-2020 has predicted slight increases in domestic supply, domestic demand, and import trends. On the other hand, it also predicted a sharp decline in the export demand trend between those same years. This study contributes to the literature by providing policymakers and other energy policy stakeholders a reliable, forward-looking analysis of the potential condition of the domestic and international bioenergy markets in the EU28 region through the end of 2020.
\end{abstract}

Keyword: Bioenergy markets; Bioenergy supply; Bioenergy demand; Bioenergy export; Bioenergy import 